\title{
Scenario and Strategy Planning for Transformative Supply Chains within a Sustainable Economy
}

Ani Melkonyan (Corresponding Author) ${ }^{1^{*}}$

Klaus Krumme ${ }^{2}$,

Tim Gruchmann ${ }^{3}$,

Stefan Spinler ${ }^{4}$

Terry Schumacher ${ }^{5}$,

Raimund Bleischwitz ${ }^{6}$

$1^{*}$ Associate Professor at the University of Duisburg-Essen, Centre for Logistics and Traffic, Address: Oststraße 99, 47057 Duisburg, Germany, Mob.: +49 1629326 391, E-mail: ani.melkonyan@uni-due.de

${ }^{2}$ Executive Director of the Centre for Logistics and Traffic, University of Duisburg-Essen, Joint Centre Urban Systems, Address: Oststraße 99, 47057 Duisburg, Germany, E-mail: klaus.krumme@ uni-due.de

${ }^{3}$ Professor for Logistics, Westcoast University of Applied Sciences, Address: Fritz-Thiedemann-Ring 20 25746 Heide Germany, E-mail: gruchmann@fh-westkueste.de

${ }^{4}$ Professor for Logistics management at WHU - Otto Beisheim School of Management, Director KühneInstitute for Logistics Management, Address: Campus Vallendar, Burgplatz 2, 56179 Vallendar, Germany, Email: stefan.spinler@whu.edu

${ }^{5}$ Associate Professor of Engineering Management at Rose-Hulman Institute of Technology, Address: 5500 Wabash Avenue, Terre Haute, IN 47803 the USA, E-mail: schumach@rose-hulman.edu

${ }^{6}$ Professor in Sustainable Global Resources, Head of Department Bartlett School Env, Energy \& Resources, Faculty of the Built Environment, University College London, Institute for Sustainable Resources, Address: ISR, Central House, 14 Upper Woburn Place London, WC1H 0NN, the UK, E-mail: r.bleischwitz@ucl.ac.uk

\section{Abstract}

Supply chain effectiveness and general societal prosperity, as well as economic and ecological productivity will be highly affected in the next decades, entailing challenges for the supply chain and logistics sector. Thereby this sector plays a significant role within the transformation process of economic systems, yet the capacities of it remain up till now underestimated. This paper suggests a holistic approach to assess transformation potential of the supply chain and logistics sector towards more sustainable economic systems while defining innovative business strategies to meet future macroeconomic developments. This is achieved through an integrated assessment of production and consumption systems, considering the interests of the key stakeholders. Moreover, the paper combines advanced methods to develop future macroeconomic scenarios and to assess the strategic business opportunities of the supply chain and logistics sector addressing societal developments, e.g. new consumption patterns. The analysis relies on modern theories of Environmental and Ecological Economics, contributing to transformation theories. Moreover, the innovative role of supply chain and logistics management in achieving sustainable macroeconomic goals at regional and international levels is addressed.

The results of the scenario analysis show that the innovation potential is the highest if the consumers exert pressure on the industry and the global governance policy sets favorable conditions for the supply chain/logistics sector to implement innovative and sustainable strategies. To address this scenario, the logistics service providers should extend their business portfolios, becoming a "lead sustainability service provider" (6 PL). If both governmental regulations and consumer requirements for sustainability are at a low level, the innovation rate in the sector can slightly increase, if the logistics service providers focus solely on economic 
performance indicators, such as cost and time efficiency, by applying new technologies or management methods. This scenario represents a realistic case, since the logistics providers are forced to innovate their business models to a certain extent, due to high competition in the sector. Based on the findings, a strategy roadmap of the supply chains and logistics sector is developed in the sense of a transformative force to address future potential macroeconomic changes, providing managerial implications and policy recommendations.

Keywords: sustainable macroeconomics, sustainable supply chains, scenario-strategy development, sustainable consumer, transformation roadmap

\section{Introduction}

Supply chains are likely to drastically change due to interdependent regional impacts of climate change (Challinor et. al., 2017), rapid urbanization (Satterthwaite et al., 2010), demographic developments (Rolfe, 2013), resource overconsumption (Hoekstra and Wiedmann, 2014) and related shifts in demand patterns. According to the "Turn Down the Heat series" 3-rd report, "warming of about $1.5^{\circ} \mathrm{C}$ above pre-industrial times is already locked into the Earth's atmospheric system by past and predicted greenhouse gas emissions", having significant regional effects on climate change (World Bank Report 3, 2014). These effects are expressed in more frequent severe droughts, increased risks in food and water security, and represent a high likelihood of global supply bottlenecks or even deadlocks in the life supporting systems of the societies (IPCC, 2014). The risk of supply insecurity will be even more intensified in the course of global demographic developments, if not very profound changes in raw material extraction, production, management of value and supply chains, as well as qualitative transformations at the consumer side take place. The increased risk of supply insecurity is highly influenced by the unsustainable global resource consumption within the value creation process of modern products (from material extraction, design and production, supply chains to consumption and use) (Bleischwitz et al., 2018). Despite the progress achieved in material efficiency and substitution in various sectors, the past decades have seen a steady rise in the material intensity. The regeneration capabilities of the basic ecological systems have already been exceeded (Rockström et al., 2009; Rockström and Klum, 2015). Moreover, it is projected that under existing trends, resource extraction will increase $119 \%$ from 2015 to 2050 (from 84 to 184 billion tons per annum), while greenhouse gas emissions will increase by $41 \%$ (HatfieldDodds et al., 2017). These changes are driven by doubling of the value of global economic activity (Geng et al., 2019).

This background highlights the need to develop economic rationale for designing and operating global supply chains in a sustainable manner. Within the last one and a half decade, a growing body of literature have contributed to the sustainable supply chain management (SSCM) with a stronger integration of various sustainability issues (Carter and Rogers 2008, Seuring and Müller 2008). Notwithstanding, the "proactive" role of supply chains within transformative macroeconomic system has so far been under-exposed. Thus, fulfilling this gap, the given study aims at bringing together business priorities of global supply chains and the macroeconomic parameters with highest impact on reshaping the business models from logistics perspective (Research Objective - RO 1). Furthermore, we aim at designing transformation pathways towards a sustainable economy (RO 2). For this, we analyze the global supply chains from nature to consumers for each resource, their interaction (resource nexus) and connection with the Sustainability Development Goals (SDGs) at regional and international levels. Thereby the socio-economic supply systems and their distribution, recycling and re-use functions in the sense of circular economy, as well as development of innovative business models are addressed. Not only sharing economy models, but also extension of business portfolios are considered once discussing innovation in the business models.

To unlock transformation potential for an increased sustainability performance, different driving factors and challenges for the future scenarios by the year 2030 are investigated on the example of Germany as a highly 
industrialized country. The scenarios were built taking into consideration dynamical changes in the macro factors with highest impact on business environment, e.g. climate change, policy decisions, societal and consumer trends/lifestyles, meanwhile relying on the modern theories of ecological and environmental economics. Within the frames of the given paper, the following research questions are addressed:

1. What are the driving macro (external) factors for possible future scenarios?

2. What kind of strategies should the supply chain and logistics sector employ, in order to address probable future macroeconomic scenarios in a sustainable way?

3. What are promising transformation pathways towards a sustainable economy?

The answers to these question will help countries and communities worldwide to establish inclusive and sustainable development agendas, to hold global warming below $2^{\circ} \mathrm{C}$, preferably under $1.5^{\circ} \mathrm{C}$, according to Paris Agreement (Rogeli et al., 2016). While parties to the Paris Agreement act nationally, production and consumption systems are global. Thus, improving global supply chain and logistics management is a contribution to strengthening sustainable transformation processes, meanwhile empowering both producers and consumers within the process of the climate action. This will enable the policymakers and supply chain members to facilitate integrated logistics strategies, balancing the sustainable development fueled by globalization, consumption patterns, market competition and exploration of new markets.

Figure 1 below provides an overview on the paper structure.

Section 2 summarizes the literature on the concepts of sustainable economy linking those to supply chains and their transformation strategies. Section 3 explains the research design, describing the methods of scenario and strategy development. Macroeconomic trends and key factors influencing scenario development within supply chain and logistics sector are presented in Section 4.1. Strategies and their evaluation for the future scenarios are discussed in section 4.2 and 4.3. A roadmap of transformative strategies is presented in section 4.4. Section 5 discusses the key findings and provides concluding remarks along with the outlook.

\section{Literature review}

Current global socio-economic and political trends highlight the need for a better understanding of future developments within global economic systems from the sustainability perspective. Because of high complexity of transformation processes towards sustainable economic systems, long-term challenges characterized by uncertainty and complexity have to be addressed. An adequate approach for doing so is development and assessment of future scenarios utilizing both quantitative and qualitative approaches. The future scenarios should not only address uncertainty and risks of long-term changes, but also help exploring different alternative pathways (Fauré et al., 2017). Quantitative methods rely on both simple and complex models. Simple or equilibrium models consider time series extrapolations of trends assuming a move from a present state towards a more balanced future state. Since some states/systems cannot be extrapolated from past values, exploratory methods or computer-aided simulations are used (Moallemi et al., 2017). In contrary to the quantitative tools, qualitative assessment methods might better fit the purpose of developing long-term transformative scenarios. The combination of quantitative and qualitative methods arguably entails a solid framework to include a comprehensive set of sustainability aspects within global and complex economic systems and supply chains. Clearly, this kind of integrated scenarios cover many aspects, such as climate futures, different possible and internally consistent socioeconomic developments. One good example of this kind of complex scenario framework is a Scenario Matrix Architecture, which is based on coupling of so-called Shared Socioeconomic Pathways (SSPs). The SSPs deal with population, economic growth, education, urbanization and the rate of technological development, considering the Representative Concentration Pathways (RCPs), which represent greenhouse gas concentration trajectories. (IPCC, 2014; CarbonBrief, 2018). 
Supply Chain Management (SCM) can be used for defining transformation process of sustainable and innovative production - consumption systems (Seuring and Müller, 2008), since SCM is considered as a driver of and driven by the complexity of the respective value creating networks (Agrawal et al., 2015; Lan et al., 2018). Therefore, our study contributes to the development of theoretical concepts linking sustainable economic theories (Ecological Economics, Environmental Economics, Recourse-based View theories) to SCM literature, meanwhile combining qualitative and quantitative analysis of scenario and strategy development. The rationale of these complex interactions is that only proactive strategies to innovate business models may lead to achievement of sustainable economy goals defined by regional and international governments, while considering dynamic changes in production-consumption patterns. In order to precisely understand the interaction among these macroeconomic factors and to estimate their future mutual influence on supply chains, a holistic analysis of the key factors driving the transformation towards a sustainable economy is necessary, where this paper also contributes to. Thus, we carry out a literature analysis on macroeconomic concepts in respect to sustainability at the first stage to set the frame of our study.

\subsection{Macroeconomic Framework: Sustainable Economy Concepts}

A sustainable economy can be defined as being low-carbon, resource efficient and socially inclusive (UNEP, 2016; Loiseau et al., 2016). It entails improved human well-being and reduced inequalities to protect future generations from environmental risks and ecological scarcities (Jackson and Victor, 2011). The macroeconomic landscape has a tremendous impact on the decisions made by economic agents, associated with optimized production, distribution and consumption of the products and services. To understand this impact, the interaction and the feedback mechanisms among macroeconomic parameters, e.g. employment, economic growth and inflation, demand and prices of natural resources, as well as the environmental damages have to be analyzed in detail. This kind of analysis results in the definition of effective environmental policies to ensure smooth transformation processes of economic systems.

Environmental and ecological economics serves as a good basis to explore causal feedbacks among environmental and macroeconomic parameters for a sustainable economy. Although being conceptually connected, ecological and environmental economics show different emphasis in their conceptual baselines. Providing insights for sustainability transitions, environmental economics is closely related to cleaner production and resource efficiency, whereas ecological economics relies merely on the concepts of industrial ecology or circular economy (Daly and Townsend, 1993; Hueting, 2010; Loiseau et al., 2016). Generally, ecological economists reject the growth models based on interactions between environment and economy (Edenhofer et al., 2014), questioning the assumption that rational, utility- or profit-maximizing behavior by firms and consumers will favor an optimal, equilibrium growth path (Taylor et al., 2016). In contrast, environmental economists claim that "sustainable economy", which deals with decreased pressure on resources, climate change and emissions, can at the same time ensure economic growth and employment. In addition to these main concepts, some other approaches, such as the bio-economy (more related to environmental economics) and Product-Service Systems (PSS, linked to ecological economics), have been identified as promising concepts to reach sustainable development goals. Besides these more macroeconomic concepts, Resource-based view (RBV) or the Natural Resource-based view (NRBV) theories could serve as good instruments for companies to implement sustainable economy strategies. The rationale behind this is that advantage by a company can be gained, if it develops distinct capabilities and can leverage resources that are rare, valuable, inimitable/substitution-resistant, organizationally specific, and heterogeneously distributed (Tate and Bals, 2018). Here, the NRBV perspective on the contingent nature of resources and capabilities allowed researchers to draw specific links between environmental and financial performance (Hart and Dowell, 2011). Although Hart's (1995) key strategic capabilities of pollution prevention, product stewardship and 
sustainable development foster green logistics practices, the logistics service providers' impact on the (socially) sustainability performance of a company or supply chain is contingent.

Despite some conceptual differences, all these theoretical macroeconomic approaches are seeking to develop better analytical frameworks to understand economy-environment interactions at a macro scale, meanwhile providing tools to manage the transition towards a sustainable economy (Fontana and Sawyer, 2016). These frameworks and approaches mainly consider global material resources and their efficient use, discuss green technology and technological decoupling from economic growth. Furthermore, they consider balancing mechanisms between global consumption and production systems through international trade, recycling and circular economy, as well as policy options and levers to control pollution. Meanwhile these concepts refer to the environmental, economic, technological and political risks associated with economic growth (WEF Global Risks, 2019; UNEP, 2016), making the transformation towards sustainable economy extremely complex.

Summarizing the literature analysis on existing concepts of sustainable economy, the interrelated key drivers of transformation process have been identified, which sets the framework of this paper: (1) Global demand and consumption systems; (2) Financial systems: Taxes and financial incentives; (3) Societal changes: Demographics and Employment rates; (4) Resource efficiency and Global Climate Change. The describing factors of these systems and their trends are used to develop the macro scenarios, which give precious information for the strategy and decision making within supply chains.

\subsection{Global Supply Chains influencing trends}

To achieve sustainable transformation of global supply chains, a coordinated development between strategic and basic/operational perspectives should take place within the boundaries of macroeconomic developments. From the strategic and commercial perspective, the most important issue is the balancing among environmental and economic factors at a macro level (Neto et al., 2009). The main challenges for balancing are managerial complexity, network imbalance, customer priorities and technological and legislative uncertainties (Abbasi and Nilsson, 2016). Representing physical flows, international trade heavily relies on transport chains, which represent a series of efficiently organized logistical operations ensuring the continuity along supply chains. Hence, the improvements in logistics performance indicator (LPI) generally favor increase in the trade volumes, along with trade openness, urbanization, and industrialization (Liu et al., 2018). Yet, being focused on LPIs, planning of logistics operations may not necessarily be based on taking the most direct path, but the path of least cost. Therefore, the quality and quantity of trade and transport-related infrastructure may have significantly negative impact on the environment, which is reflected in increased resource consumption or release of emissions (Khan et al., 2018). The increase in upstream resource requirement for trade are explained by increasing share of higher-processed goods in total trade and by more intermediate goods being traded between countries, before satisfying final demand. For EU-27, Zaman and Shamsuddin (2017) showed that industrialization and trade liberalization policies increase carbon-fossil emissions, thus claiming that supply chain and logistics activities should be closely linked to the country's national sustainability agenda. Although transport related activities represent just one part of modern supply chain and logistics services, it is still core to the service portfolios. According to the European Commission report, transport related industries contribute almost $4.6 \%$ to GDP and employ around 10 million people, which is approximately $4.5 \%$ of the total employment in the EU-28. The transport industry heavily relies on oil, consuming approximately $96 \%$ of its energy needs. Therefore, its contribution to GHG (greenhouse gas) emissions was calculated to be around $20 \%$ during the year 2017 (European Commission, 2018). Through evaluating Environmental Kuznets Curve (EKC), Nassani et al. (2017) confirmed the inverted U-shaped relationship between financial development and nitrous oxide emissions, and U-shaped relationship between economic growth and GHG emissions. 
These negative environmental impacts of global supply chains, associated with increased international trade may completely cancel out a potentially better allocation of extraction and production processes through world trade. Therefore, with increased globalization, strategic planning of sustainable supply chain management (SSCM) practices (Carter and Easton, 2011; Min and Kim, 2012) under different logistics activities is crucial, in order to achieve sustainable development goals. The strategic planning of SSCM and logistics management positively influences operational performances of the sector through reduction of externalities (Lai and Wong, 2012). Reviews done on SSCM at operational level show that sustainability practices are mostly focused at the firm level and are linked to e.g. Corporate Social Responsibility (CSR) (Bhardwaj, 2016); sustainable supply network management (Eskandarpour et al., 2015); environmental purchasing (Chin et al., 2015); environmental marketing and management (Ansari and Qureshi, 2015); reverse logistics (Beh et al., 2016); sustainability labeling schemes (Van Dam and van Trijp, 2016); LCA (Young, 2018): waste management (Ahmad, 2016); energy usage (Shi et al., 2015).

Both strategic and operational planning levels of supply chains are supported by the digitization of the sector nowadays. Digital transformation opens up far-reaching advantages for companies in SCM, such as increased transparency and reliability, improved delivery capability, new service models and higher flexibility. The impact of digitization is very high at the strategic planning level, helping the decision-makers to better align the supply chain according to factors such as costs, time, quality, risk mitigation and environmental friendliness. With the help of digital technologies, the dynamic behavior of supply chains can be illustrated and analyzed, thus reducing the costs of a sudden fluctuation in demand enormously. The effects of digitization at operational level may even be higher. The operational processes are changing steadily through the integration of machines and robots for tour and route planning (Bräysy and Hasle, 2014), supply chain planning (Zijm and Klumpp, 2016), returns management (Choi et al. 2018), layout planning (Lien and Cheng, 2012), dimensioning of production capacities or the design of the material flow system (Bierer et al., 2015). In general, it is expected that increase in efficiency, delivery reliability, supply chain transparency, predictability and flexibility will be achieved through implementation of new digital technologies. These optimistic expectations do not take into consideration that counterproductive rebounds can occur, particularly through digitization, if complex system feedbacks stay unconsidered (Galvin, 2015). With respect to specifications in logistics and supply chains in and for a sustainable economy, this issue still needs more attention to be paid on.

Summing up the literature review, the framework for developing resource-efficient and effective strategies for global supply chains related to sustainable macroeconomic system is set. The framework considers continued economic globalization as the driving force of trade and investments, the growing demand for just-in-time delivery concepts, the adoption of agile manufacturing and business practices enabled by digitization. Agile and innovative corporations with international supply chains depend heavily on modern logistics services. Their continuous efforts to offer innovative services to consumers, such as same-day delivery or last mile delivery through new digital or connected approaches, are influenced by and at the same time shape consumers' lifestyles for example in the shopping context by retailers or at the community level through social marketing (Joerss et al., 2016). Therefore, behavioral insights, which include psychology, marketing and behavioral economics should be used in the design, implementation and evaluation of corporate or governmental policies (Lehner et al., 2015). If these strategies promote beneficial behavior for individuals or society as a whole, meanwhile promoting policy effectiveness, "nudging" applies (Mont et al., 2014). Many companies are already building robust nudge tools to efficiently deal with various organizational and strategic challenges (McKinsey, 2019). Simplification and framing of information, changes to the physical environment, or the use of social norms are examples of applied nudging tools. These tools increase organization's reactivity to rapid changes in consumer behavior, hence fostering its agility and performance (Michalek et al., 2016). This is increasingly crucial for competitiveness especially in the supply chain and logistics, considering the rapid growth of on-line retail. Thus, 
consumer expectations, their environmental awareness and willingness to pay for sustainable logistics services plays a decisive role in creating the fundamental framework of this paper.

\section{Research Design}

To develop reliable scenarios we combine the results from the literature analysis and from expert workshops into exploratory scenarios, which can generally be both qualitative (storytelling) and quantitative (van Vliet and Kok, 2015). The advantage of the exploratory scenarios is their capability to describe different developments of social, economic and environmental factors, firstly applying participatory techniques, and afterwards quantifying those (RO 1). Furthermore, the advantage of combining quantitative and qualitative scenarios is the identification of robust actions, which are effective in the different socio-environmental contexts (Amer et al., 2013). Based on these action roadmap, recommendations for smooth transformation towards sustainable economy can be formulated, which corresponds to the RO 2 of this paper.

During the expert workshops the factors with the highest impact on supply and consumption patterns were explored and evaluated through applying a mixed-method approach of STEEP (Social, Technological, Environmental, Economic and Political). This method was applied in order to combine external factors into scenarios and to map them (Section 3.1). Moreover, we have used the results from 500 queries reflecting consumer preferences and sustainability awareness, as well as their perception of logistics processes, in order to provide the workshop participants with sufficient information from the consumer side. These results implied a higher impact of sustainability-related attributes, such as environmental impact and working conditions on the willingness of the consumers to include consider sustainable logistics services into their decision-making process (Stöckigt et al., 2018).

For developing transformational strategies and evaluating the most appropriate ones Scenarios to Strategies (S2S) method was used (Section 3.2), which also relies on quantitative approaches.

Data were collected from several sources, in particular

$>$ scenario development workshops with experts (4 days, 45 participants, aim: identification of external and internal factors, combination of them into scenarios and strategies),

$>$ an evaluation workshop (2 days, 40 participants, aim: evaluation of the best scenario-strategy match).

\subsection{Scenario exploration and development workshops with STEEP method}

The scenario development workshop series lasted four days aiming at identification of external and internal factors and their combination into scenarios and strategies to achieve RO 1. Consistent with theoretical sampling, participant selection of the workshops was conducted based on the participants' ability to generate new insights that would support theory development. The choice of the workshop participants (in total 45) followed the principle of triple helix stakeholdership (business practice, public management and policy as well as science) (Etzkowitz and Leydesdorff, 2000). Representatives of the business practice were medium-sized and multi-national logistics service providers active in B2C (business-to-consumer) market of western European countries, covering both fashion and food domains (35 participants). All of them had an experience in implementation of sustainability practices into their businesses. Public management was represented by the departments of logistics and traffic as well as digitization of the city halls of Duisburg and Essen (three participants). To cover consumer perspective, seven participants were invited from the Consumer Organization North Rhine-Westphalia, the Research Institute of Sustainable Nutrition, Collaborative Center for Sustainable Production and Consumption, and Center for Media and Health (the Netherlands).

STEEP method is usually applied in marketing or business-related fields, with the aim to identify external factors that could have impact on the operation of a certain organization or system and lay out of the control 
of the organization itself. Besides qualitative techniques, such as participatory and brainstorming techniques, STEEP combines also several statistical tools, like CIB (Cross-Impact Balance Analysis) and multidimensional scaling (Lorenz and Veenhoff, 2013). CIB is used to analyze both the qualitative and quantitative impact networks (Weimer-Jehle, 2016). The aim of CIB is to construct consistent images of the network behavior by providing values into the relations between the factors of an impact network. Moreover, multidimensional scaling (MDS) technique was applied to analyze the similarities of data on a set of objects used in several fields, including inter-correlations, ratings or indices of any kind. The main reason to use the MDS is to obtain a graphical visualization of the data structure, display the essential information, smoothing the noise of the data statistics. The graphical representation or mapping the scenarios helps to deal with the high complexity of a system with numerous elements.

The STEEP analysis was applied according to the schematic proposal of Figure 2 (Lorenz and Veenhoff, 2013). During the STEEP analysis a dedicated list of macroeconomic factors influencing the supply chains was created by the workshop participants. Accordingly, the collected factors were specified by the spheres of the STEEP model.

The other stages of the scenario creating process will be explained in the section "Results", simultaneously explaining the central findings of the analysis.

\subsection{Scenarios to Strategies (S2S) evaluation}

In this section we show how to design strategy maps in order to bring predictive qualities to key performance indicators by linking them to perceived cause-and-effect relationships. Strategy maps seem more often to extrapolate past performances and are seldom sufficiently linked to possible future dynamics (Buytendijk et al., 2010). We argue that scenario analysis plays an important role in the design of strategy maps, providing opportunities to the companies in preparing themselves for multiple plausible futures, not only the one they expect to happen. Therefore, scenario-based strategy method has the advantage for organizations to face strategic uncertainty in a more effective way and make them more sustainable in the longer term (Bodwell and Chermack, 2010). For this, three approaches are used: a) problems with predictions (studying what happened in the past), b) system thinking (interlinkages among the parameters relevant for the decision-making), and c) strategy as 'fit' (organization's ability to fit into the environment it operates in) (van der Merve, 2008). All three approaches have been considered in this paper, while applying S2S method.

The S2S used here is a method, which was initially developed as an alternate strategic planning method in the electric utility industry. The S2S is a process to guide a group of participants in defining a set of scenarios, which are later used to test strategies the group develops. The process begins by distinguishing factors, and choices/actions that the planning entity could undertake. A list of factors and choices is developed which is discussed to define a shared understanding among the participants. Strategies are developed by including all choice dimensions and selecting combinations of points on each choice range. A common starting point is to define 'Business as Usual', which is the current choice pattern. A key strength of scenario methods is the exploration of 'What if?' possible futures. After the list of choices has been defined, alternate strategies can be generated. The group often begins with combinations of choices they wish to understand better and these guide the combinations of choices included in strategies to be tested. Criteria for evaluating the performance of a strategy are developed. For this, the balanced scorecard approach of considering several dimensions is recommended. When the group has defined a set of scenarios and a set of strategies, each strategy is considered in each scenario and a score is determined using performance criteria (Fig. 3). Within the scope of this paper, we focused only on the set of strategies, like Scenario-based Strategy, System Thinking, Strategy and Alignment. Some aspects of Change Management and Organizational Culture have also been included, while designing the strategies in details $(\S 4.2)$. The others are beyond the scope of the given paper. 
Given the fact that sustainability performance of the strategies is crucial, three sustainability criteria haven selected - Price for logistics service (PS); environmental protection (ENV) and social standards (SS). The evaluation of a strategy in a scenario, using these criteria, produces an 'Outcome' in the S2S, which was carried out with the same forty five participants during a two-day workshop.

\section{Results: Scenario and strategy building}

\subsection{Scenario Development}

Macroeconomic trends influencing future developments of the supply chains and logistics sector have been summarized from the literature analysis $(\$ 2.1)$ and presented during a series of scenario and strategy development workshops with the key actors. These eight trends referred to Globalization, Digitization, Policy regulation, Resource availability, Climate change and air pollution, Open innovation (development of new business models), Societal and consumption trends. In order to create joint understanding of the trends' impact on the sector, these have been described by choosing two factors (attributes) each, resulting in sixteen key factors. To keep the process of scenario building structured, the selected key factors were classified into different content-related spheres of society, technology, environment, economy and policy (STEEP) (Table 1).

Table 1: List of the selected sixteen key factors.

\begin{tabular}{lllll}
\hline \multicolumn{1}{c}{ Social } & \multicolumn{1}{c}{ Technological } & Environmental & Economic & Political \\
\hline Urbanization & $\begin{array}{l}\text { Big data analytics and } \\
\text { optimization models } \\
\text { Technology use to } \\
\text { promote transparency } \\
\text { along the value chains }\end{array}$ & $\begin{array}{l}\text { Share of } \\
\text { renewable energy }\end{array}$ & $\begin{array}{l}\text { Land use changes } \\
\text { International trade }\end{array}$ & $\begin{array}{l}\text { Environmental } \\
\text { regulations }\end{array}$ \\
$\begin{array}{l}\text { Demographics } \\
\text { (volatility } \\
\text { enhancement) }\end{array}$ & $\begin{array}{l}\text { Policies to adopt } \\
\text { internalization of } \\
\text { externalities }\end{array}$ \\
$\begin{array}{l}\text { Environmental } \\
\text { awareness of } \\
\text { consumers }\end{array}$ & Release of GHG \\
$\begin{array}{l}\text { Growth of sharing } \\
\text { economy models }\end{array}$ & Raw material & $\begin{array}{l}\text { prices } \\
\text { and ants }\end{array}$ \\
$\begin{array}{l}\text { Established } \\
\text { associations } \\
\text { /partnerships }\end{array}$ & & $\begin{array}{l}\text { Population } \\
\text { income }\end{array}$ & \\
\hline
\end{tabular}

In the next step, possible developments of the key factors were combined into a matrix, creating a portfolio with four possible options for each factor. Firstly, detailed information on scoping the scenario field, possible impacts of macroeconomic trends on global supply chains, as well as system boundaries has been provided to the participants. Each option was discussed with the participants during the scenario development workshop. An example is shown in Figure 4 for two trends - "Globalization" and "Consumer Orientation Patterns". The factors international trade and price pressure describe the trend of "Globalization", while environmental awareness (expressed in willingness to pay for sustainable logistics) and population income are the descriptive factors for the change in "Consumer Orientation Patterns". Portfolios for the remaining six trends with their factors are presented in Appendix, Fig. A.1 a-f.

The four options for the trend "Globalization" are shortly described in the following.

\section{Trend 1: Globalization (Fig. 4, left-hand side)}

Option A: The level of international trade is low, but price pressure is high. This option represents a local market with high competition and low sales prices. 
Option B: Both the international trade level and the price pressure are high. This situation is typical for an international market with increased competition and low sales prices.

Option C: Both the international trade level and the price pressure are quite low. This option is common for a locally regulated market with high subsidies.

Option D: The combination of high level of international trade and low price pressure characterizes monopolistic economy within a deregulated market.

After creating all possible portfolios for eight trends, the next stage was devoted to the scenario development itself. Optional future states of each key parameter defined in the last stage were checked pair-wise with the future states of all the others, through applying am evaluation range of -2 to +2 . Here, -2 means that it is deemed impossible for the given two states to coexist, and +2 indicates mutual occurrence between two portfolios of randomly chosen factors. This analysis caused a development of a $32 \times 32$ matrix (eight trends with four options each). The options being estimated as mutually exclusive combinations ( -2 and -1$)$ have been eliminated to create consistent scenarios. In order to combine the remaining options into clusters, which represent than the final scenarios, the multidimensional scaling analysis was carried out, showing the graphical representation (common space) of the options classified after STEEP method.

As a result, four clusters of the future options have been identified, describing the scenarios of the future supply chains considering macroeconomic trends. Even though the resulting common space obtained from the multidimensional scaling displays the interrelationships between the future options, it neglects the type of dimension in which they are displayed. Thus, a further analysis to define the dimensions of the scenarios is required. Having the future options organized by type and arranged in a cardinal representation, the dimensions or axes of the graphic were determined based on the similarities and differences among all the options. After finding a common pattern, the dimensions were defined and discussed with the experts during the workshops. The $\mathrm{X}$-axis describes the policy regulations, Y-axis environmental awareness and lifestyles of the consumers and Z-axis is the innovation rate within the economies, expressed in the size of the bubbles (Fig. 5, left-hand side). The characteristics of each scenario is shown in the right-hand side of Figure 5.

\section{Scenario 1: "Sustainable Governance for a Green and Inclusive Economy" (SG)}

Scenario 1 considers sustainable economic development with high share of public and private investments in new supply chain concepts. This enhances innovation, enabled by application of innovative digital technologies, which may increase transparency within the system. Moreover, this may help consumers to make environmentally friendly decisions, while improving sustainability awareness of the society. The government plays also a decisive role within this scenario by developing new urban development concepts, utilizing e.g. "Smart City" approaches. This would promote renewable energy production, strengthen the public transport network, shorten commute distance and prevent land use changes. Moreover, the government would make strict environmental restrictions on emission release, resource exploitation, carbon and water footprint of the sector, by making constraints on e.g. driving hours, speed, and vehicle ownership. Except environmental restrictions, innovation rate could be enhanced by public incentives to create favorable conditions for logistics service providers (LSP) to make their services more sustainable. These conditions might include e.g. longer time-span to access low emission areas, access to areas restricted for conventional fuel vehicles, free parking during a short time/better parking slots and conditions.

\section{Scenario 2: "Sustainable Consumers" (SC)}

Individualized lifestyles and high rates of urbanization are the main descriptors of this scenario. Individualized lifestyles are expressed in inventing, designing and producing own products by consumers themselves (prosumers), which is partially facilitated by 3 -D printers and so called "fab lab" structures. This trend leads 
to an increase in regional trade flows. Only data and raw material travel over the world, causing a drastic decrease in long-distance transport of finished products. Hence, local and regional logistics becomes increasingly important in this scenario.

Presence of new digital technologies and increasing environmental awareness of the consumers also favors development of sharing/collaborative economy models (in Customer-to-customer: C2C). Sharing and circular economy solutions enable quick and easy responses to consumer needs by matching supply and demand in an efficient way. Such business models mainly rely on:

- Use of IT systems, typically available via web-based platforms, such as mobile "apps" or internet-enabled devices, to facilitate peer-to-peer transactions.

- Reliance on user-based rating systems for quality control, ensuring a level of trust between consumers and service providers who have not met previously.

- Flexibility of the workers who provide services via digital matching platforms in deciding their typical working hours.

- Digital matching firms rely on their own tools and assets to provide a service.

\section{Scenario 3: "Efficiency and Technology Driven Economic Growth" $(E C)$}

This scenario assumes digitization to revolutionize business with the growing influx of technological innovation. Besides hardware-oriented trends like robotics, the software-based digital technologies create fundamental change in processes, operations, functions, and even within entire business models. With respect to individual technologies, a series of technological solutions play a central role within the ongoing digitization trend in the supply chain and logistics sector. Among others, miscellaneous sensors, video cameras, cyberphysical systems, augmented and virtual reality, as well as the internet of things and services were mentioned by the key actors.

Apart from the introduction of the individual technologies to different application areas of global supply chains, which is solely efficiency driven, this scenario assumes that global governance lacks at a clear strategy of a holistic digital transformation towards sustainable economy, being expressed in deregulated economic growth. Resources are extracted in a harmful way causing strong environmental degradation. The consumers are also environmentally ignorant and ownership focused. Moreover, technological progress here is described by digital divide. Thus, digital transformation means more than the sheer move to digital business. It is a fundamental and accelerating transformation of business activities to make full use of the promising digital technologies and their impact across the industry and society in a strategic manner. Therefore, in order digitization serves to the efficient transformation of the sustainable economy, policy interventions are absolutely necessary, like in the Scenario 1.

\section{Scenario 4: "Business as Usual" (BaU)}

Scenario 4 "Business as Usual" is the least case scenario. Supply chains firstly benefit from economic growth and continuous increase in consumption, until resources get scarcer, natural disasters pile up and supply disruptions become more frequent. A lack of political regulations for environmental reverse globalization prohibits the importance of short value chains. Technological development will become recessive. With no structural changes, the same urban development and logistics concepts cause expansion of built-up areas and high rate of land use change. Within this scenario the society is focused solely on economic growth. Some participants believed that countries being focused on economic growth would become the world's principal engine of new demand growth and spending power. However, it is important to highlight that numerous factors and trends block the exponential growth of these economies. High level of urbanization will lead to more polluted environment and natural resource scarcity, limiting the further economic growth. 


\subsection{Strategy Development}

When deciding on the right business transformation strategy for a LSP, discussing all the operational factors, which the company has an influence on, is the first step. Thus, after combining the external factors into scenarios, at the next stage the internal/operational factors were discussed with the participants in the evaluation workshop. The combination of these factors resulted in development of the firms' strategies to face possible future scenarios in a sustainable way.

For this, firstly action fields relevant for decision making processes and the choices which can be made within each action field were identified during the workshop. These action fields are: design of the supply chains; transport and location planning; investment in new technologies (in transport, packaging, warehousing); communication strategies and consumer-orientation (Figure 6). The choices in each action field were later combined into three main strategies. Note, that there were initially four strategies: in addition to the three strategies listed below, there was another one, named 'Old-School Logistics'. Since the descriptors of this strategy were very similar to those in $\mathrm{BaU}$ with the only difference in the field of communication, the participants decided to merge these two strategies into $\mathrm{BaU}$ in the last stage of the workshop, which was the evaluation of scenarios and strategies.

The current trends relevant both for strategic and operational levels within the sector cause significant changes in the business models of logistics. The performance-determining share of logistics in the value-adding interplay between production and consumption has thus steadily increased. The typical logistics domains of transport, delivery and storage have expanded to a variety of cross-sectional tasks in rendering comprehensive industrial services for the entirety of production and supply systems. In 1960, the companies acted as only a subcontractor (1 PL). In the 1990s, the strategies of Carrier (2 PL) and Logistics operator (3 PL) and by the mid-2000s the strategies of Supply Chain Optimizer (4-5 PL) were developed (Selviaridis and Spring, 2007; Dhayanidhi et al., 2011, Gruchmann et al., 2018). Using this popular classification scheme of 1PL to 5PL business model, each derived strategy was aligned with certain business model types. Combining these scenarios with possible strategies allows for the inclusion of a new business type to the 1PL to 5PL scheme, the so-called Lead Sustainability Service Provider (6PL) (Gruchmann et al., 2018).

\section{Strategy 1: "Lead Sustainability Service Provider" (LSSP) (6 PL)}

In this strategy the integration of production, supply and consumption systems into an umbrella of strong sustainability is enforced (Pelenc and Ballet, 2015). Against this, physical and digital supply network structures and functions play the central role as merged and holistically managed, planned and controlled physical distribution, stakeholder, data/ information and collaboration networks. Consumer empowerment through communication strategies, collaborative PSS/ prosumer integration into decision making as well as advanced vertical supply chain information management (co-flows with respect to environment -water, carbon, etc.- as well as social impacts) represent powerful innovation for the LSSP. The flow of goods and products including related sustainability assets are completely transparent and traceable to all supply chain members, particularly to the end-customer. Advanced use of information technologies, such as big data/ prescriptive data analytics, artificial intelligence or blockchain concepts, often in combined technology platforms is implemented. All possible transport modes and structurally related logistics services are considered and the most sustainable are preferred since externalities of transport, storage and transshipment have been internalized into service prize building mechanisms as well as regulatory framework conditions (e.g. environmental tax policy). Supply network optimization leads to maximum environmental friendly and economically profitable solutions, under changed framework conditions with respect to (pulling) society, mindsets and (pushing) regulations. Transport reduction/ avoidance is a central parameter for sustainable supply chain planning and LSSP create alternative value added services with respect to information logistics to customers (both B2B and B2C). Through 
networking, parts of data and information management as well as physical flows of goods can be outsourced to society (the "crowd") if needed. The storage and transshipment, particularly on the critical urban last mile, is carried out in city hubs, micro depots, meanwhile providing innovative on-demand solutions and new business models as well as specialized last mile service providers. Means of transport for single deliveries generally cover all available options (including autonomous and electric/ fuel cell or other alternative "high tech" vehicles, as well as drones, robots, or cargo-bikes) depending on their in situ sustainability related performances. This leads to radical shifts of the mass transport modal split towards more sustainable transport forms (including higher shares of modern waterborne and railway transport) as well as new structures of transport chains with respect to integrated production and consumption systems (regional and urban supply as well as temporal shifts in supply induced by shifting consumption modes).

Closed Loop SCM is standardized in many industrial commodity chains and enables value creation through re-manufacturing or refurbishment strategies. The co-flows of packaging are largely digitized and adapted to the logistical and recycling/ re-use requirements.

\section{Strategy 2: "Efficient Logistics" (EL) (4-5 PL)}

Fourth party logistics (4 PL) is an integrator that assembles the resources, capabilities, and technology of its own organization and other organizations to design, build and run comprehensive supply chain solutions using information and communication technologies (ICT). As digital technologies enable supply chains to become more global, the international logistics industry has been researching the development of 4 PL services, i.e. the realization of full-scale operation of e-procurement. A key function of the $5 \mathrm{PL}$ is to aggregate the demands of the 3 PL into a bulky volume in order to be able to negotiate more favorable rates with airlines and shipping companies. To increase cost efficiency in the focal company, 5 PL logistics assumes value added services (network planning, assembly, part production steps, take back systems, etc.). This strategy focuses on efficiency improvements both in an ecological and an economic sense. Nevertheless, no integrative sustainability approach is used. Multi-channel and crowd-logistics concepts bundling as many streams as possible are used to deliver to the end customers. Delivery to the end customers is carried out using electric vehicles and cargo-bikes. Picking and storage of the goods takes place mainly in a central warehouse. Some investments might be done in zero-emission buildings and new cooling systems. Digitization enables new forms of packaging, utilizing new materials in reduced quantities. Overall, this strategy can be described as strongly efficiency- and technology-driven. Organizations that have successfully implemented a 4 -5 PL model have benefited from improved service levels, reduced logistics costs, and greater flexibility to deal with changing business needs. Key for the success of this strategy is the willingness of the customers to pay. Increased trust between firms and their SCM providers is enhanced by economic imperatives, technological innovations, integration of information flows at horizontal and vertical levels, as well as market competition and managerial ability to provide advanced logistics services.

\section{Strategy 3: "Business as Usual” (BaU) (1-3 PL)}

"Business as Usual" follows the more traditional business strategy of a third-party logistics provider (3 PL), targeting a single function. 3 PL provides logistics services for companies for a part or sometimes all of their supply chain management. The delivery takes place exclusively to the end-consumers' home mainly via the modality of the road. Important instruments are bundling and the use of central warehouses. Conventional technologies are used: conventional trucks with combustion engines transport the goods. This strategy is strongly driven by the growth and cost efficiency and relies heavily on fossil fuels.

\subsection{Scenario-to-Strategy}

Applying the S2S method in the final stage, four scenarios and the three strategies were evaluated within a matrix using criteria of sustainability, such as price for logistics services (PS), environmental protection 
(ENV), and social standards (SS). The intersecting field was given the note 0 if the future situation is worse than the current one, 1 - no changes are expected and 2, if the situation is expected to improve (Table, righthand side of the Figure 7). The values given to each criterion were aggregated at the end, in order to estimate the best strategy addressing future scenarios (Fig. 7, left-hand side).

As shown in Figure 7, following Strategy 1 - "Lead Sustainability Service Provider - LSSP", a logistics firm would be clearly better off for all the scenarios. If the logistics company follows Strategy 2 - "Efficient Logistics - EL", the situation would be improved if future Scenario 1 is to apply. In any other case, it performs worse, except Scenario 2, where no actual change is considered. The Business as Usual (BaU) strategy performs better if consumers become more environmentally aware and if they are willing to pay for sustainable logistics services, as well as if the Scenario 4 takes place. In any other situation, it is clearly the strategy with the worst performance, thus identifying the urgent need to innovate the business models.

\subsection{Transformation pathways towards sustainable economy}

Possible pathways of economic transformation are shown in Figure 8, where the four main scenarios and three strategies are mapped. For creating the transformation pathways, estimation of the scenarios similarity to today's situation, desirability and probability of the best scenario to occur in the future has been discussed in the last workshop with the same stakeholders who created the scenarios. To guide the process of mapping the transformative pathways from today's situation towards more desired scenario, the following questions have been discussed:

- Which of the scenarios is the "most similar to today"?

- Which of the scenarios are the ones we would like to see?

- Which scenario do we expect to actually happen?

With this visualization it is possible to highlight today's situation of the supply chains with the corresponding possible divergences as expected scenarios. It is based on the majority of the circumstances apparent today which can be described mainly by traditional economic systems with less environmentally oriented consumers and integrated political decisions.

Scenario development showed that the innovation potential in the sector of supply chain and logistics is the highest if there is a pressure coming from both the government and consumers to become sustainable. Considering no substantial changes in governmental restrictions and consumer requirements for sustainability staying at a low level, the Scenario 4 - 'Business as Usual: BaU' might continue to be the possible future pathway. In that case, the innovation rate in the sector is slightly higher, if the logistics providers focus on Key Performance Indicators (KPI) of efficiency, such as economic (cost savings) and time (fast delivery) efficiency, while applying new digital technologies. In this current situation, the logistics providers are forced to innovate their business models to a certain extent, due to high competition and disruptions in the sector. From today's situation on, "Business as Usual" scenario can develop into two main directions: either it can continue to be fostered without significant change in economic structure or policies will leading to stagnation (1). The alternative might be that due to resource scarcity and climate change induced vulnerability a switch towards sustainable future and innovative economic models will emerge to balance the market (2). In the first case, the winners will be big companies (mergers and alliances), which are the major players in the market. This, in its turn, will lead to unequal competition and market failure, resulting in higher prices and environmental ignorance by the big players. In the second case, there is a chance to switch to innovative sharing economy models, as it is the best solution for SMEs to cooperate and increase their power. This chance will case the development pathway from Scenario 4 to Scenario 2 - Sustainable Consumer (SC). Slight changes in the consumption behavior will lead to a rapid development of sharing economy models at least for B2C and $\mathrm{C} 2 \mathrm{C}$ business, which might be accompanied by certain regulations on a local level, as well as gained additional 
knowledge skills. In that case, Scenario 4 (BaU) might develop into the same direction, as Scenarios 1 (SG) and Scenario 3 - 'Efficiency driven economic growth: EG'. In the case of increase in sustainable consumption patterns and integrative/sustainability oriented policy regulations, Scenario 3 might develop towards Scenario 2 and Scenario 1 - 'Sustainable governance for green and inclusive economy: SG'. The latter represents the desired future, where societies manage to combat climate change, leading to high environmental protection and development of new forward oriented supply chain concepts. These would favor the sector to become sustainable, fast, flexible, stable and locally adapted. These favorable conditions to innovate the company strategies are further mapped in Figure 8, while the discussion of the roadmap is carried out in the next section.

\section{Discussion}

\subsection{Strategy roadmap addressing macroeconomic trends}

\section{Theoretical implications}

Current macroeconomic trends, accompanied with unsustainable resource use and environmental degradation highlight the urgent need for the transformation of economic systems. Transformation means reducing the negative emissions and environmental impacts of economic activities, decreasing resources use to get back into the range of natural sustainability, meanwhile creating new opportunities for the societies to consume in a sustainable way (Bontoux and Bengtsston, 2015).

Transformation potential of economy towards more sustainable systems has been assessed by using various model approaches of ecological economics (Safarzynska and van den Bergh, 2010), complex systems (Zeppini et al. 2014), socio-economic systems, behaviour and dynamics (System Dynamics - SD models: Papachristos, 2017). However, these model approaches are still weak in representing qualitative changes of different normative aspects, such as new fields of social activity, new ways of consuming (Köhler et al., 2018). This gap is filled by the present paper, where integrated, qualitative and quantitative methods have been applied to evaluate the transformation potential of the economic system. This was achieved by developing future macroeconomic scenarios influencing the supply chain and logistics sector, which is the driver of economic system, meanwhile causing unsustainability within the system. A strategy roadmap for this sector was created in the sense of a transformative or 'pro-active' force to address the future potential changes. Sustainable Governance scenario represents a combination of several potential changes and is evaluated to be the desired future for sustainable macroeconomic systems. Moreover, literature analysis shows that it might also be realistic and achievable one, since it is characterized by e.g.

- strict environmental policy on emissions (55\% of $\mathrm{CO}_{2}$ reduction by 2050 ; Ministry of Nature Protection of Germany, 2019: national target)

- large investments in logistics infrastructures (BMVI, 2019: national investment strategy)

- a highly digitized economy with supply chain transparency (Kagermann, 2015: global estimation)

- increase in number of business models within sharing and circular economy (Carra and Magdani, 2016; Pushmann and Alt, 2016: global estimation)

\section{Managerial implications}

These macroeconomic trends relevant both for strategic and operational levels within the logistics sector will cause significant changes in the business models. These changes are driven by a strong integration of information and communication technology (ICT) based services towards a direction of a more integral control and enrichment of value-added services in terms of contract or system logistics (Zijm and Klumpp, 2016). The performance-determining share of innovative logistics in the value-adding interplay between production and consumption has thus steadily increased. 
In this line, our first finding states that the logistics sector should develop innovative and sustainable concepts through broadening the portfolio of sustainable added-value services in order to meet the desired future of Scenario 1 - Sustainable Governance. The development of sustainable added-value services by the logistics companies corresponds to the Strategy $1-6$ PL Lead Sustainability Service Provider, which enables SSCM practices. Positive effects of SSCM practices on sustainable supply chain performance have already been empirically proven (Ahi and Searci, 2013; Kashmanian, 2015). This highlights the fact that the firms need to collaborate globally in advocating SSCM practices to ensure firm's success. In evaluating SSCM practices, basically quantitative analysis dominate, such as equilibrium models, multi-criteria decision analysis or analytical hierarchy process, without really taking into account qualitative approaches (Seuring, 2013). Combining qualitative and quantitative approaches, we argue that 6 PL should be operationalized in the sense of Ecological Economics as "shared responsibility in the supply chain" and with respect to "critical capitals for supply and value chain management" (Krumme, 2019). Thereby we define key principles of a strong supply chain sustainability as.

1. Stewardship of critical capitals (CC): particularly with respect to natural capital stocks and flows, CC may not fall below certain values of qualities/quantities.

2. Supply Chain Responsibility (SCR) is a shared task and should be measurable, transparent and understandable within value creating supply chain networks for all stakeholders.

3. Equity of (critical) capitals must be well distributed among producers, traders, service providers and consumers.

This brings us to our second statement is that only the companies, which are proactively driving the transformation of the macroeconomic systems towards more sustainable patterns, will be successful in the long-run. A survey-based analysis of Harms et al., 2012 reveals that large German companies mainly implement risk-oriented SSCM strategies, which means that instead of applying innovative supply chain concepts (or business-opportunity-oriented approach) they prefer 'only' adoption of supplier evaluation and selection. Moreover, until now external pressure to implement SSCM practices clearly outweighs the proactive role in the transformation process (Mohanty and Prakash, 2014).

Our third statement argues that development of the successful strategies should follow a system thinking approach, addressing the most relevant macroeconomic aspects. System thinking approach in strategy development relies on prediction thinking and management thinking foresights, thus arising the need to combine qualitative and quantitative approaches (Rebs et al., 2018). System thinking advances SSCM and sustainable logistics practices especially when focusing on innovation, learning and sense-making (Nilsson and Gammelgaard, 2012). One aspect of system thinking is that n-order supply chains should be considered in business practices from the point of origin in the first-order supply chains in order to enhance corporate efforts of SSCM (Svensson, 2007). The other aspect is that supply chains go beyond the traditional point of consumption, considering the consumer as driving force of the supply system. General SCM underestimates the demand and consumption dimensions and neglects natural limits of demand. Even Demand Chain Management (DCM) is linking SCM to marketing in a one-directional way aiming at maximization of sales by optimizing SCM and marketing measures. In contrast, 6 PL strongly enhances sustainable consumption patterns. Altmann, 2015 supports our statement to include consumption perspective into the sustainable strategy development by creating a Mixed Integer Linear Programming Supply Chain Model based on a German production company that incorporates a demand function influenced by sustainability requirements.

\subsection{Policy recommendations}

The trigger to drive these transformative changes is willingness of the global policies to develop integrative and inclusive governmental patterns. Yet, application of sustainable (green and inclusive) economy concepts, 
which consider dematerialization, servicing and investments into environment and natural capital, are complex, requiring systemic changes in economies and societies. Even though the investments are mainly done by the private sector, governments play a central role in guiding these investments towards greening the economy. Thus, policy regulations are urgently required in order to promote sustainable economies, in particularly transforming supply chain and logistics sector. The sector fuels the global economy, by continuously expanding the system, becoming more complex and having higher impact on environment. In addition, regulations and frameworks, incentives and reward systems in the interest of society can strongly promote necessary innovations and practices while stopping opposing dynamics. In the case of the dominant role of the modern logistics and supply chain sector for production, trade and consumption, this can be a lever which, in the spirit of the paper, makes transformative supply chain structures and services for a sustainable economy possible.

Governmental policy recommendations for transformation towards sustainable economy are summarized below. These rely on macroeconomic parameters with high impact on SSCM and logistics practices. The governmental levers on these macroeconomic parameters are in line with international literature.

1. The governments themselves should implement sustainability practices into their decision-making processes, such as governmental expenditures and accounting (Loiseau et al., 2016).

2. Integration of the economy into ecosystem, considering the environmental limits and various aspects of well-being and working patterns is necessary. This can be done by inclusion of different income groups into economic systems (through taxing levels), meanwhile understanding the consumer behavior for shifting consumption patterns (nudging) (Hardt, L. and O'Neill, D., 2017).

3. Production systems of disaggregated industries should also be strongly reflected into concepts of environmental economics, including different business models with different behaviors.

4. Policy regulation practices as governmental subsidies, tax exemptions or low interest rates for using renewable energy within logistics operational process (e.g. eco-design vehicles), penalties on polluted systems, fostering cooperation between logistics sector and governmental authorities should be implemented. This can be done through adoption of certification schemes (Khan et al., 2018).

5. Better understanding of logistics performance indicators at a country level, facilitating evaluation of supply chains efficiency, service and infrastructure development. For this, macrologistics costs are one of the most suitable indicator, being measured by the percentage of sales or turnover, absolute costs and percentage of GDP (Akoudad and Jawab, 2018). With the costs being low at a national level, competitiveness among industries is enhanced, trade and sales are increased, providing opportunities for new markets entrance. This indicated medium-term policy through trade liberalization.

6. Long-term policies to strengthen the supply chain processes at national and international levels should be implemented, considering international standardization of products, services and operations according sustainability requirements, which would attract global markets. Moreover, the importance of human (social) factors involvement within the process of logistics and supply chain development must also be highlighted (Aldakhil et al., 2018)

7. The proposed policies should be evaluated for their efficiency over time and across countries, through better understanding of logistics performance at country level, meanwhile considering dynamic interactions at local, national and regional scales.

\section{Conclusion and Outlook}

Applying a holistic approach, this paper addressed socio-economic, environmental, technological and political aspects in order to develop macroeconomic scenarios and sustainable strategies for supply chain and logistics sector, defining the transformational pathways towards a sustainable and inclusive economy. This was 
achieved through a combined assessment of economic systems, meanwhile considering the interests of the key stakeholders. Four possible scenarios were developed, among which Scenario 1 - Sustainable Governance for Green and Inclusive Economy was evaluated to be the most desired and more realistic one. It considers the current macroeconomic trends on e.g. strict environmental regulation, a highly digitized economy with supply chain transparency, increasing cooperation among the supply chain members (in the form of sharing economy), being enabled by emerging new digital technologies.

Based on these scenarios, logistics service providers may adjust their business models with regard to their strategic positioning in the market and regulatory system, particularly by pro-actively developing and implementing innovative and sustainable concepts through broadening their portfolio of sustainable addedvalue services. These concepts will extend to the overall planning of supply chain networks (Strategy 1: Lead Sustainability Service Provider) in terms of configuration and coordination of supply chain partners, partial production steps, assemblies, and shaping of retailing businesses. Newer logistics value-added services configure high quality after sales services as well as the re-integration of products into lifecycles, as re-use, recycling, refurbishment or remanufacturing, in frames of circular economy. To do so, the 6PL "Lead Sustainability Service Provider" model includes modern logistics/ SSCM a responsible instance for the design, coordination, management and control of sustainable operational networks in integrated production, supply and consumption systems. To be able to move these transformation levers, however, changes in the management paradigms in classical SCM to fulfil the 6PL role are indispensable. Future management implications must be understood here as the central aspects of strong supply chain sustainability and systems thinking.

From the policy perspective, inclusive governmental patterns need to penetrate policy maker's actions. To support these actions, the present study provides basic guidance, focusing primarily on the logistics and supply chain sector as enabler of the comprehensive transformation towards a sustainable economy. Future scenario research in this field can focus on other sectors, such as the energy and housing sector, to develop cross-sectoral guidelines and policies. However, innovations so far are limited to the lack of considering important support, demand and reward aspects to change basic conditions. Here, particularly qualitative case studies can help to make best practices more visible and are necessary for further progress. For example, it is possible to investigate to what extent in the status quo innovation strategies of the Lead Sustainability Service Provider can have economic success in the market and generate environmental and wider societal benefits. Future work could also include the sustainability assessment of the proposed strategies in a case study and take into account the expansion of the logistics companies' business portfolio. Another issue could be the scalability of these kind of business models, where supply chains integrate regional, national or international production and consumption systems into strong sustainability services. Changed framework conditions can be mirrored in computer-based simulations and be blended with data obtained from case studies. This would have high orientation value for business actors, but also political / social decision-makers.

\section{Acknowledgments}

The research activities of this study are connected to the project "ILoNa" (Innovative Logistik für nachhaltige Lebensstile - Innovative Logistics for Sustainable Lifestyles: 2015-2018). The project was funded by the Ministry of Research and Education in Germany (Research for Sustainable Development: Section for Sustainable Economies) and the project management was carried out by the German Aerospace Center (DLR). 


\section{References}

1. Abbasi, M., Nilsson, F., 2016. Developing Environmentally Sustainable Logistics: Exploring Themes and Challenges from a Logistics Service Providers' Perspective. Transportation Research Part D: Transport and Environment 46, 273-283.

2. Abukhader, S., Jönson, G., 2004. Logistics and the Environment: Is it an Established Subject? International Journal of Logistics Research and Applications 7(2), 137-149.

3. Ahi P., Searcy C., 2013. A comparative literature analysis of definitions for green and sustainable supply chain management. Journal of Cleaner Production 52, 329-341.

4. Ahmad, W. N. K. W., Rezaei, J., Tavasszy, L. A., de Brito, M. P., 2016. Commitment to and preparedness for sustainable supply chain management in the oil and gas industry. Journal of environmental management 180, 202213.

5. Akoudad K., Jawab F., 2018. Evaluating Total Logistics Costs at Macro and Micro Level: Literature Review. International Journal of Engineering Research \& Technology 7/2, 319-325.

6. Aldakhil, A., Nassani, A., Awan, U., Abro, M., Zaman, K., 2018. Determinants of Green Logistics in BRICS Countries: An Integrated Supply Chain Model for Green Business. Journal of Cleaner Production, 10, 861-868.

7. Amer M., Daim T. U., Jetter A., 2013. A review of scenario planning. Futures 46, 23-40.

8. Ansari, Z. N., Qureshi, M. N., 2015. Sustainability in Supply Chain Management: An Overview. IUP Journal of Supply Chain Management 12(2), 24-46.

9. Antal, M., Van den Bergh, J., 2013. Macroeconomics, Financial Crisis and the Environment: Strategies for a Sustainability Transition. Environmental Innovation and Societal Transitions 6, 47-66.

10. Beh, L. S., Ghobadian, A., He, Q., Gallear, D., \& O'Regan, N., 2016. Second-life retailing: a reverse supply chain perspective. Supply chain management: an international journal 21(2), 259-272.

11. Beske-Janssen, P., Johnson, M. P., Schaltegger, S., 2015. 20 years of performance measurement in sustainable supply chain management-what has been achieved? Supply chain management: An international Journal 20(6), 664680.

12. Bhardwaj, B. R., 2016. Role of green policy on sustainable supply chain management: A model for implementing corporate social responsibility (CSR). Benchmarking: An International Journal 23(2), 456-468.

13. Bierer A., Götze U., Meynerts L., Sygulla R., 2015. Integrating Life cycle costing and life cycle assessment using extended material flow cost accounting. Journal of Cleaner Production 108/B, 1289-1301.

14. Bleischwitz R., Spataru C., VanDeveer S. D., Obersteiner M., van der Voet E., Johnson C., Andrews-Speed P., Boersma T., Hoff H., van Vuuren D. P., 2018. Resource nexus perspectives towards the United Nations Sustainable Development Goals. Nature Sustainability 1, 737-743

15. BMWI, 2019. Federal transport infrastructure plan. Retrieved from https://www.bmvi.de/DE/Themen/Mobilitaet/Infrastrukturplanung-Investitionen/Bundesverkehrswegeplan-2030/ bundesverkehrswegeplan-2030.html

16. Bodwell W., Chermack T.J., 2010. Organizational ambidexterity: Integrating deliberate and emergent strategy with scenario planning. Technological forecasting and social change 77/2, 193-202.

17. Bontoux L., Bengtsston D., 2015. 2035: Paths towards a sustainable EU economy, Sustainable transitions and the potential of eco-innovation for jobs and economic development in EU eco-industries. Joint Research Center, Science for Policy Report, https://ec.europa.eu/jrc

18. Bräysy, O., Hasle, G., 2014. Software Tools and Emerging Technologies for Vehicle Routing and Intermodal Transportation. Vehicle Routing: Problems, Methods, and Applications, Second Edition. Society for Industrial and Applied Mathematics, 351-380.

19. Buytendijk F., Hatch T., Micheli P., 2010. Scenario-based strategy maps. Business Horizons 53/4, 335-347

20. CarbonBrief, 2018. https://www.carbonbrief.org/explainer-how-shared-socioeconomic-pathways-explore-futureclimate-change.

21. Carra G., Magdani N., 2016. Circular Business Models for the Built Environment. Ellen Macarthur Foundation. Retrieved from https://www.ellenmacarthurfoundation.org/assets/downloads/ce100/CE100-CoPro-BE_BusinessModels-Interactive.pdf.

22. Carter, C., Easton, P., 2011. Sustainable Supply Chain Management: Evolution and Future Directions. In: International Journal of Physical Distribution \& Logistics Management 41(1), 46-62.

23. Challinor, A. J., Adger, W. N., Benton, T. G., 2017. Climate risks across borders and scales. Nature Climate Change 7(9), 621.

24. Chin, T. A., Tat, H. H., Sulaiman, Z., 2015. Green supply chain management, environmental collaboration and sustainability performance. Procedia CIRP 26, 695-699.

25. Choi, T. M., Wallace, S. W., Wang, Y., 2018. Big data analytics in operations management. Production and Operations Management 27(10), 1868-1883.

26. Coto-Millán, P., Agüeros, M., Casares-Hontañón, P., Pesquera, M., 2013. Impact of Logistics Performance on World Economic Growth (2007-2012). World Review of Intermodal Transportation Research 4(4), 300-310. 
27. Dafermos, Y., Nikolaidi, M., Galanis, G., 2017. A Stock-flow-fund Ecological Macroeconomic Model. Ecological Economics 131, 191-207.

28. Daly, H., Townsend, K., 1993. Valuing the Earth: Economics, Ecology, Ethics. Cambridge: MIT Press.

29. Dhayanidhi K., Azad A., Narashiman K., 2011. The Use of Third Party Logistics Services - A Literature Review. International Journal of Operations System and Human Resource Management 1/1-2, 29-43.

30. Edenhofer, O., et al., 2014. Mitigation of Climate Change. Contribution of Working Group III to the Fifth Assessment Report of the Intergovernmental Panel on Climate Change. Cambridge: Cambridge University Press.

31. Eisenhardt, K. M., Graebner, M. E., 2007. Theory building from cases: Opportunities and challenges. Academy of Management Journal 50/1, 25-32.

32. Eskandarpour, M., Dejax, P., Miemczyk, J., Péton, O., 2015. Sustainable supply chain network design: an optimization-oriented review. Omega 54, 11-32.

33. Etzkowitz, H., Leydesdorff, L., 2000. The Dynamics of Innovation: From National Systems and 'Mode 2" to a Triple Helix of University-Industry-Government Relations. Research Policy 29(2), 109-123.

34. European Commission Report on Mobility and Transport, 2018. https://ec.europa.eu/transport/factsfundings/evaluations/reports-year_en.

35. European Environment Agency, 2014. Resource-efficient Green Economy and EU Policies. Publications Office of the European Union.

36. Fauré E., Arushanyan Y., Ekener E., Miliutenko S., Finnveden G., 2017. Methods for assessing future scenarios from a sustainability perspective. European Journal of Futures Research 5(17), doi.org/10.1007/s40309-017-01219 .

37. Fontana, G., Sawyer, M., 2016. Towards Post-Keynesian Ecological Macroeconomics. Ecological Economics 121, 186-195.

38. Galvin, R., 2015. The ICT/electronics question: Structural change and the rebound effect. Ecological Economics 120, 23-31. doi:10.1016/j.ecolecon.2015.08.020.

39. Geng Y., Sarkis J., Bleischwitz R., 2019. How to globalize the circular economy. Nature 565, 153-155.

40. Gruchmann T., Melkonyan A., Krumme K., 2018. Logistics Business Transformation for Sustainability: Assessing the Role of the Lead Sustainability Service Provider (6PL). Logistics 2/25, doi:10.3390/logistics2040025.

41. Hardt, L., O'Neill, D., 2017. Ecological Macroeconomic Models: Assessing Current Developments. Ecological Economics 134, 198-211.

42. Harms D., Hansen E.G., Schaltegger S., 2012. Strategies in Sustainable Supply Chain Management. An Empirical Investigation of Large German Companies. Corporate Social Responsibility and Environmental Management 20, 205-2018.

43. Harris, J., 2009. Ecological macroeconomics: Consumption, Investment and Climate Change. Harris, J., Goodwin, N. (Hrsg.), Twenty-First Century Macroeconomics: Responding to the Climate Challenge. Cheltenham: Edward Elgar.

44. Hart, S. L., 1995. A natural resource-based view of the firm. Academy of Management Review 20/4, 986-1014.

45. Hart, S. L., Dowell, G., 2011. A natural-resource-based view of the firm: fifteen years after. Journal of Management 37/5, 1464-1479.

46. Hatfield-Dodds S., Schandl H., Newth D., Obersteiner M., Cai Y., Baynes T., West J., Havlik P., 2017. Assessing global resource use and greenhouse emissions to 2050, with ambitious resource efficiency and climate mitigation policies. Journal of Cleaner Production 144, 403-414.

47. Havenga, J., Simpson, Z., De Bod, A., 2013. Macro-logistics Trends: Indications for a more Sustainable Economy. Journal of Transport and Supply Chain Management 7(1), 1-7.

48. Hoekstra, A. Y., Wiedmann, T. O., 2014. Humanity's unsustainable environmental footprint. Science 344/6188, 1114-1117.

49. Hosie P., Sundarakani B., Tan A. W. K., Koźlak A., 2012. Determinants of Fifth Party Logistics (5PL): service providers for Supply Chain Management. Int. J. Logistics Systems and Management 13(3), 287-316.

50. Hueting, R., 2010. Why environmental sustainability can most probably not be attained with growing production. Journal of Cleaner Production 18(6), 525-530.

51. IPCC, 2014. Climate Change 2014: Synthesis Report. Contribution of Working Groups I, II and III to the Fifth Assessment Report of the Intergovernmental Panel on Climate Change (Core Writing Team, R.K. Pachauri and L.A. Meyer (eds.)). IPCC, Geneva, Switzerland.

52. Jackson, T., Victor, P., 2011. Productivity and Work in the 'Green Economy': Some Theoretical Reflections and Empirical Tests. Environmental Innovation and Societal Transitions 1(1), 101-108.

53. Joerss, M., Schroeder, J., Neuhaus, F., Klink, C., Mann, F., 2016. Parcel delivery. The future of last mile.

54. Kagermann H., 2015. Change Through Digitization-Value Creation in the Age of Industry 4.0. Albach H., Meffert H., Pinkwart A., Reichwald R. (eds) Management of Permanent Change. Springer Gabler, Wiesbaden

55. Kashmanian, R. M., 2015. Building a sustainable supply chain: Key elements. Environmental Quality Management, 24/3, 17-41.

56. Khan, S., Zhang, Y., Anees, M., Golpîra, H., Lahmar, A., Qianli, D., 2018. Green Supply Chain Management, Economic Growth and Environment: A GMM Based Evidence. Journal of Cleaner Production 185, 588-599. 
57. Köhler J., de Haan F., Holtz G., Kubeczko K., Moallemi E., Papachristos G., Chappin E., 2018. Modelling Sustainability Transitions: An Assessment of Approaches and Challenges. JASSS, 21(1) 8, 201, doi: 10.18564/jasss.3629

58. Krumme K., 2019. Research and Innovation Perspectives on Integrated Supply Chains in a Sustainable Economy. In book: Innovative Logistics Services and Sustainable Lifestyles - Interdependencies, Transformation Strategies and Decision Making, Springer, DOI: 10.1007/978-3-319-98467-4_14.

59. Lien, L. C., Cheng, M. Y., 2012. A hybrid swarm intelligence based particle-bee algorithm for construction site layout optimization. Expert Systems with Applications 39(10), 9642-9650.

60. Lehner M., Mont O., Heiskanen E., 2015. Nudging - A promising tool for sustainable consumption behaviour? Journal of Cleaner Production 134/A, 166-177.

61. Liu, J., Yuan, C., Hafeez, M., Yuan, Q., 2018. The Relationship between Environment and Logistics Performance: Evidence from Asian Countries. Journal of Cleaner Production 204, 282-291.

62. Loiseau, E., Saikku, L., Antikainen, R., Droste, N., Hansjürgens, B., Pitkänen, K., Leskinen, P., Kuikman, P., Thomsen, M., 2016. Green Economy and Related Concepts: An Overview. Journal of Cleaner Production 139, 361371.

63. Lorenz, U., Veenhoff, S., 2013. Integrated Scenarios of Sustainable Food Production and Consumption in Germany. Sustainability: Science, Practice and Policy 9(2), 92-104.

64. McKinsey \& Company, 2019. How to nudge your way to better performance: Build a nudge unit to leverage behavioral insights, https://www.mckinsey.com/business-functions/organization/our-insights/the-organizationblog/how-to-nudge-your-way-to-better-performance

65. Melkonyan A., Krumme K., 2019. Innovative Logistics Services and Sustainable Lifestyles: Interdependencies, Transformation Strategies and Best Practices. Springer Nature, ISBN 978-3-319-98466-7, DOI 10.1007/978-3-31998467-4

66. Michalek G., Meran G., Schwarze R., Yildiz Ö., 2016. Nudging as a New “Soft” Policy Tool - An Assessment of the Definitional Scope of Nudges, Practical Implementation Possibilities and Their Effectiveness. Economics Discussion Papers, http://www.economicsejournal.org/economics/discussionpapers.

67. Min, H., Kim, I., 2012. Green Supply Chain Research: Past, Present, and Future. Logistics Research 4(1-2), 39-47.

68. Moallemi, E. A., Aye, L., de Haan, F. J., Webb, J. M., 2017. A dual narrative-modelling approach for evaluating socio-technical transitions in electricity sectors. Journal of Cleaner Production 162, 1210-1224.

69. Mohanty, R. P., \& Prakash, A. (2014). Green supply chain management practices in India: an empirical study. Production Planning \& Control, 25(16), 1322-1337.

70. Mont O., Lehner M., Heiskanen E., 2014. Nudging. A tool for sustainable behaviour? Swedish EPA report 6643, Lund University.

71. Nassani, A., Aldakhil, A., Abro, M., Zaman, K., 2017. Environmental Kuznets Curve Among BRICS Countries: Spot Lightening Finance, Transport, Energy and Growth Factors. Journal of Cleaner Production 154, 474-487.

72. Neto, J., Walther, G., Bloemhof, J., Van Nunen, J., Spengler, T., 2009. A Methodology for Assessing Eco-Efficiency in Logistics Networks. European Journal of Operational Research 193(3), 670-682.

73. Nilsson F, Gammelgaard B., 2012. Moving beyond the systems approach in SCM and logistics research. International Journal of Physical Distribution \& Logistics Management 42/8-9, 764-783.

74. OECD report on future demand for materials, 2018. https://www.oecd.org/environment/waste/highlights-globalmaterial-resources-outlook-to-2060.pdf.

75. Papachristos, G., 2017. Diversity in technology competition: The link between platforms and sociotechnical transitions. Renewable and Sustainable Energy Reviews 73, 291-306.

76. Pelenc, J., Ballet, J., 2015. Strong sustainability, critical natural capital and the capability approach. Ecological Economics, 112, 36-44

77. Puschmann T., Alt R., 2016. Sharing Economy, Business and Information Systems Engineering 58/1, 93-99.

78. Rebs T., Brandenburg M., Seuring S., 2018. System dynamics modeling for sustainable supply chain management: A literature review and systems thinking approach. Journal of Cleaner Production 208, DOI: $10.1016 /$ j.jclepro.2018.10.100

79. Rockström, J., Klum, M., 2015. Big World, Small Planet: Abundance within Planetary Boundaries. Yale University Press.

80. Rogeli, J., Den Elzen, M., Höhne, N., Fransen, T., Fekete, H., Winkler, H., Schaeffer, Sha, F., Riahi, K., Meinshausen, M., 2016. Paris Agreement Climate Proposals Need a Boost to Keep Warming Well Below 2 C. Nature 534(7609), 631-639.

81. Rolfe J., 2013. Predicting the economic and demographic impacts of long distance commuting in the resources sector: A Surat basin case study. Resources Policy 38(4), 723-732.

82. Safarzynska, K., van den Bergh, J. C. J. M., 2010. Demand-supply coevolution with multiple increasing returns: Policy analysis for unlocking and system transitions. Technological Forecasting and Social Change 77(2), $297-317$.

83. Satterthwaite D., McGranahan G., Tacoli C., 2010. Urbanization and its implications for food and farming. Phil. Trans. R. Soc. B 365, 2809-2820, doi:10.1098/rstb.2010.0136. 
84. Selviaridis K., Spring M., 2007. Third Party Logistics: A Literature Review and Research Agenda. The International Journal of Logsitics Management 18/1, 125-150.

85. Seuring S., 2013. A review of modeling approaches for sustainable supply chain management. Decision Support Systems 54, 1513-1520.

86. Seuring, S., Müller, M., 2008. From a Literature Review to a Conceptual Framework for Sustainable Supply Chain Management. Journal of Cleaner Production 16(15), 1699-1710.

87. Shi, P., Yan, B., Shi, S., Ke, C., 2015. A decision support system to select suppliers for a sustainable supply chain based on a systematic DEA approach. Information Technology and Management 16(1), 39-49.

88. Stöckigt, G., Schiebener, J., Brand, M., 2018. Providing sustainability information in shopping situations contributes to sustainable decision making: an empirical study with choice-based conjoint analyses. Journal of Retailing and Consumer Services 43, 188-199.

89. Svensson G., 2007.Aspects of sustainable supply chain management (SSCM): conceptual framework and empirical example. Supply Chain Management: An International Journal, 12/4, 262-266.

90. Taylor, L., Rezai, A., Foley, D., 2016. An Integrated Approach to Climate Change, Income Distribution, Employment, and Economic Growth. Ecological Economics 121, 196-205.

91. United Nations (UN), 2019. Population dynamics, retrieved from https://www.un.org/development/desa/en/news/population/2018-revision-of-world-urbanization-prospects.html.

92. UNEP, 2016. IRP Report, World Resources Forum: https://www.wrforum.org/uneppublicationspdf/resourceefficiency-economic-implications/.

93. van Dam, Y. K., \& van Trijp, H. C., 2016. Interventions to encourage sustainable consumption. Apstract: Applied Studies in Agribusiness and Commerce 10(2-3), 51-58.

94. van den Bergh, J., 2011. Environment Versus Growth - A Criticism of "Degrowth" and a Plea for "A-growth". Ecological Economics 70(5), 881-890.

95. van der Merve, 2008. Scenario-based strategy in practice: A Framework. Advances in Developing Human Resources $10 / 2,216-239$.

96. van Vliet M., Kok K., 2015. Combining backcasting and exploratory scenarios to develop robust water strategies in face of uncertain futures. Mitigation and adaptation strategies for global change 20/1, 43-47.

97. World Bank, Report No. 3, 2014. Turn Down the Heat: Confronting the New Climate Normal. http://www.worldbank.org/en/topic/climatechange/publication/turn-down-the-heat

98. Young, S. B., 2018. Responsible sourcing of metals: certification approaches for conflict minerals and conflict-free metals. The International Journal of Life Cycle Assessment 23(7), 1429-1447.

99. Zaman, K., Shamsuddin, S., 2017. Green Logistics and National Scale Economic Indicators: Evidence from a Panel of Selected European Countries. Journal of Cleaner Production 143: 51-63.

100. Zeppini, P., Frenken, K. \& Kupers, R., 2014. Thresholds models of technological transitions. Environmental Innovation and Societal Transitions 11, 54-70.

101. Zijm, H., Klumpp, M., 2016. Logistics and supply chain management: developments and trends. Logistics and Supply Chain Innovation (pp. 1-20). Springer, Cham.

\section{Appendix}

